\title{
A Study on Foreign Languages Demand in Xi'an Under the Background of "the Silk
}

\author{
Road Economic Belt"
}

\author{
Qin Wei \\ Xi'an Polytechnic University, \\ Xi'an City, Shaan Xi, 710048, China
}

\author{
Wu Hong \\ Xi' an Polytechnic University, \\ Xi'an City, Shaan Xi, 710048, China
}

Abstract - On September 7, 2013, delivering a speech at the Nazarbayev University in Kazakhstan, President Xi Jinping appealed to Asian and European countries to jointly build " the silk road economic belt". The Chinese government attaches great importance to building a new "Silk Road" economic zone. With unique geographical advantage, rich cultural heritage and rich tourism resources, Xi'an attracts much more attention in the background of "the silk road economic belt". While there are many countries take part in the new "Silk Road" economic zone, barrier-free communication is the fundamental prerequisite to develop the economy of Xi'an. Therefore, it is very important to study the foreign languages need of Xi'an. This paper makes an analysis on the characteristics of foreign languages need in Xi'an and takes an investigation on foreign languages majors of all universities in Xi'an, so as to find what kinds of foreign languages are insufficient and make some suggestions to make up the demand.

Key words- Foreign Languages Demand; Xi'an; Silk Road Economic Belt

\section{Introduction}

In the construction of the silk road economic belt and the development of the national western, Xi'an, as a new starting point of the Silk Road Economic Belt and the strategic fulcrum connecting the central with the western part of China and Europe with Asia, faces a series of new great opportunities. Xi'an is the most important transportation junction in northwestern China and it has a long history and splendid culture. As an eco-tourism city, Xi' an is famous for many places of interest and scenic spots. Based on the advantages of history, culture and transportation, the development of $\mathrm{Xi}$ 'an has attached much attention. To speed up the implementation of "the decision on major issues concerning comprehensively deepening reforms" by the third plenary session of the 18th Communist Party of China Central Committee, Xi'an will spare no effort to promote the silk road economic belt and become an important force driving the rapid development in the central and western regions.

At present, Xi'an gives full play to its advantages in the silk road economic belt including geography advantage, transportation hubs advantage, historical and cultural advantages, scientific and educational resources advantages. The city is making efforts to create "One Height, Six Centers" and striving to build the most dynamic, innovative capacity and become the leading role in construction of "the 
silk road economic belt". "One Height" means the development of open in the silk road economic belt. "Six Centers" consist of financial trade and logistics center, machinery manufacturing center, the energy storage and transportation trading center, cultural tourism center, science and technology research and development center, high-end talent training center. In order to achieve this goal, language barriers should be overcome primarily.

Therefore, it is an important issue to study the foreign languages demand of Xi'an, do research on the current situation of foreign languages majors in the universities of Xi'an, and make some suggestions to meet the foreign languages needs in the context of the silk road economic belt.

\section{Characteristics of Foreign Languages Demand in Xi'an}

According to the current situation of Xi'an under the background of "the silk road economic belt", the characteristics of foreign languages necessities can be demonstrated as follows:

The first is about English. From the macro level point of view, English as an international lingua franca continues to play a significant role in "the silk road economic belt". In other words, both sides whose languages are mutually unintelligible can still choose to use English to start marketing, communication, negotiation, trading and other activities. But with the trend of multilateral economic cooperation in China under the background of "the silk road economic belt", the demand for other foreign languages are gradually increasing. This situation reflects the demand for multilingual development trend.

The second is about Russian, Korean,
Japanese and German. As the construction of "the silk road economic belt", the biggest change in foreign languages demand is Russian. Because many of the major countries related to "Silk Road" use Russian as their mother tongue or official language. The demand in Xi' an for Russian become more and more obvious. Besides, the usage of Korean in Xi'an is relatively high and continuing to increase, especially after Samsung settled in Xi'an, as well as the establishment of the Korean Consulate in Xi'an. Meanwhile, there are some Japanese companies and the German-owned enterprises in Xi'an, which shows the demand for Japanese and German is also more evident.

The third is about Turkmen, Kyrgyz, Kazakh, Uzbek, Ukrainian, Tajik, Arabic, Farsi and so on. In the trade relations between China and the other countries in Central Asia, Kazakhstan and Turkmenistan are largest trading partners, Uzbekistan and Kyrgyzstan are the second largest trading partners, as well as Tajikistan is the third largest trade partner. Coincidentally, with the geographical advantage, Xi'an borders on Kazakhstan, Kyrgyzstan, Tajikistan, thus making its transportation convenient. Xi'an is north to Gan Long, west to Basu, east to Henan, Shandong, south to Zhejiang, and Asia-Europe continental bridge traverse it. With the development of "the silk road economic belt", Xi'an increases many international air routes, and the demand for foreign language flight attendants are also increasing. Under this kind of circumstance, grasping mutual languages and the cultural identity of the information asymmetry can reduce investment in the country, increase investor confidence, and reduce transaction costs. 


\section{Problems of Foreign Languages Majors' Setting in Xi'an}

On the basis of the research on foreign languages majors' setting of universities in $\mathrm{Xi}$ 'an, there are some problems to satisfy foreign languages need in Xi'an. The researcher has investigated 27 universities in Xi'an which set up foreign languages majors. Through the foreign language majors study of 27 universities in Xi'an, the English major is set up widely, and the number of students who learn English is the largest. At the same time, some universities offer English courses combining their school characteristics with English in different directions. For example, Shaanxi Normal University sets up English education direction; Xi'an Medical University English medical direction; Xi'an Physical Education University English sports direction, etc. In addition, Xi'an International Studies University and Xi' an Fanyi University open up many foreign languages majors, which involve English, Business English, Tourism English, Teaching English, French, application French, Russian, German, application German, Japanese, application Japanese, Oriental Languages and Cultures (Arabic, Persian, Korean, Hindi, Thai, Turkish, Urdu) and Western Languages and Cultures (Spain, Portugal, Italy).

Under the construction of "the silk road economic belt", only Xi' an International Studies University sets up 11 species of foreign languages, which shows that the demand for foreign languages majors talent in Xi'an is obviously insufficient. Among all of foreign languages majors, English and Japanese have been set up be many universities. And three universities open up Russian, respectively, Shaanxi Normal University, Xi'an Petroleum University and Xi'an International Studies
University. In terms of undergraduate enrollment in foreign languages majors, the number of foreign language professional is about 21,000. Apart from the higher number of undergraduate who study foreign languages of Xi' an International Studies University and Xi'an Fanyi University, the number of other universities is nearly 200 at average.

Although there are 25 kinds of languages related to "the silk road economic belt", for instance, Russian, Turkmen, Kyrgyz, Kazakh, Uzbek, Ukrainian, Tajik, Arabic, Farsi, German, French, Japanese, Korean, Turkish , Hindi, Urdu, Nepali, Vietnamese, Thai, Laotian, Malay, Tamil, Burmese, Khmer and so on, 14 kinds of languages still have been open up. Therefore, lacking of language teaching is against to strengthen the construction of the "Silk Road".

\section{Conclusion}

The analysis of the investigation shows that English still is the most wildly used by people. But according to the real situation of Xi'an, Russian, Korean, Japanese and German are also used by more and more people. In addition, the need of foreign languages, such as, Turkmen, Kyrgyz, Kazakh, Uzbek, Ukrainian, Tajik, Arabic, Farsi and so on has not been satisfied. Meanwhile, the foreign languages majors of all universities in Xi'an pay much attention to English, Japanese as before. It is not benefit for promoting the economic development of Xi'an. Thus, some improvements should be applied to meet the demand of foreign languages. In the one hand, the leadership of university should open up more foreign languages majors, or exchange more English students to study abroad, especially, Kazakhstan, Turkmenistan, Uzbekistan, Kyrgyzstan and Tajikistan. In the other hand, school-enterprise cooperation 
should be strengthened in order to find the market needs of foreign languages as soon as possible.

\section{Acknowledgement}

Note: This research aided financially by "graduate student innovation fund project" in Xi'an Polytechnic University, "A Study on Needs of Xi'an Foreign Language Personnel Under the Background'the Silk Road Economic Belt'." (CX2015032)

\section{References}

[1] The Decision on Major Issues Concerning Comprehensively Deepening reforms,

a) 2013 .

[2] Chen Weifeng, Qin Xiaoping. How to Develop into an International Metropolis in the Context

a) of the Silk Road Economic Belt--A Case Study of Xi'an [J]. Academics. 2015, (4): 318-322.

[3] Dang Linning, Li Yun. A Study on English Teaching for Postgraduates Under the Background

a) of "the Silk Road Culture" [J]. International Journal of Technology Management. 2014, (7):

b) 130-131.

[4] Bai Yongxiu. The In-Depth Background and Geo-Strategy for the Silk Road Economic Belt

a) [J]. Peace. 2015, (1):16-28.

[5] Ron VAN OERS. The Chinese Silk Road as World Heritage:Developing a Strategic Approach

i. for its Management [C]. Beijing Forum. 2014.11.07. 